\section{Quantification of CT bronchiectasis and its relationship to ventilation in cystic fibrosis}

\author{
Tim Rosenow
}

Structural lung abnormalities and impaired pulmonary function are key facets of respiratory disease in cystic fibrosis (CF). Over the last decade, CT and the multiple breath washout (MBW) technique have been extensively investigated and validated as clinical and research tools to measure their severity. However, little is known about the relationship between the structural and functional aspects of CF lung disease. This may in part be due to limitations inherent to visual CT scoring: in particular, the difficulty of quantification and the combined contribution of a variety of abnormalities. ${ }^{12}$ As a consequence, the concordance between lung structure and function in CF varies across studies, leading to uncertainty in how best to monitor and treat the disease. ${ }^{3-8}$

In Thorax, Verbanck and colleagues present a novel method of quantifying bronchiectasis on CT, based on counting airway segments. ${ }^{9}$ In their study, they compare the number of segments with bronchiectasis $\left(\mathrm{n}_{\mathrm{BE}}\right)$ to measures of ventilation heterogeneity from MBW, in both CF and non-CF bronchiectasis. They report that lung clearance index is significantly associated with $n_{B E}$ in both diseases. Interestingly, they also report that $\mathrm{n}_{\mathrm{BE}}$ is associated with convection-specific measures of ventilation heterogeneity from MBW: curvilinearity and Scond. ${ }^{10}$ Since bronchiectasis visible on CT predominantly consists of conducting airways, ${ }^{11}$ these results are consistent with physiologic expectations and thus are a plausible demonstration of the direct impact of structural lung disease on pulmonary function.

Correspondence to Dr Tim Rosenow, Telethon Kids Institute, The University of Western Australia, Subiaco, WA 6008, Australia; tim.rosenow@telethonkids.org.au
There are still many unresolved questions regarding structure/function relationships in CF. Longitudinal data are required in order to confirm the findings in this study, ideally including a paediatric population. In addition, defining airways as either bronchiectatic or not may be overly simplistic. Fully quantitative assessments of bronchoarterial diameters have been performed in other studies, and may offer a more complete picture of airways disease, at the cost of analysis complexity. ${ }^{12}$ Furthermore, bronchiectasis is only one component of CF structural lung disease: the contribution of trapped air, mucous plugging, and so on, as well as bronchiectasis on pulmonary function must be considered. ${ }^{4} 1314$ Nevertheless, the study by Verbanck et al is an important step towards marrying lung structure and function in CF.

Contributors The editorial was conceived and written by TR.

Competing interests None declared.

Provenance and peer review Commissioned; externally peer reviewed.

(C) Article author(s) (or their employer(s) unless otherwise stated in the text of the article) 2018. All rights reserved. No commercial use is permitted unless otherwise expressly granted.

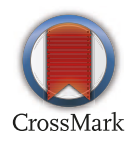

To cite Rosenow T. Thorax 2018;73:4.

Published Online First 9 October 2017

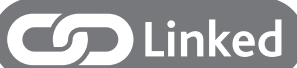

- http://dx.doi.org/10.1136/thoraxjnl-2017-210496

Thorax 2018;73:4.

doi:10.1136/thoraxjnl-2017-210917

\section{REFERENCES}

1 Szczesniak R, Turkovic L, Andrinopoulou ER, et al. Chest imaging in cystic fibrosis studies: What counts, and can be counted? I Cyst Fibros 2017;16:175-85.

2 Aziz ZA, Davies JC, Alton EW, et al. Computed tomography and cystic fibrosis: promises and problems. Thorax 2007;62:181-6.

3 Ramsey KA, Rosenow T, Turkovic L, et al. Lung clearance index and structural lung disease on computed Tomography in early cystic fibrosis. Am J Respir Crit Care Med 2016;193:60-7.

4 Rosenow T, Ramsey K, Turkovic L, et al. Air trapping in early cystic fibrosis lung disease-does $\mathrm{CT}$ tell the full story? Pediatr Pulmonol 2017:52:1150-6.

5 Horsley AR, Davies JC, Gray RD, et al. Changes in physiological, functional and structural markers of cystic fibrosis lung disease with treatment of a pulmonary exacerbation. Thorax 2013;68:532-9.

6 Fuchs SI, Gappa M, Eder J, et al. Tracking Lung Clearance Index and chest $\mathrm{CT}$ in mild cystic fibrosis lung disease over a period of three years. Respir Med 2014;108:865-74.

7 Owens CM, Aurora P, Stanojevic S, et al. Lung Clearance Index and HRCT are complementary markers of lung abnormalities in young children with CF. Thorax 2011;66:481-8.

8 Gustafsson PM, De Jong PA, Tiddens HA, et al. Multiple-breath inert gas washout and spirometry versus structural lung disease in cystic fibrosis. Thorax 2008;63:129-34.

9 Verbanck S, King GG, Zhou W, et al. The quantitative link of lung clearance index to bronchial segments affected by bronchiectasis. Thorax 2018;73:82-4.

10 Verbanck S, Paiva M, Paeps E, et al. Lung clearance index in adult cystic fibrosis patients: the role of convection-dependent lung units. Eur Respir J 2013:42:380-8.

11 Sheel AW, Guenette JA, Yuan R, et al. Evidence for dysanapsis using computed tomographic imaging of the airways in older ex-smokers. J Appl Physiol 2009;107:1622-8.

12 Kuo W, Andrinopoulou ER, Perez-Rovira A, et al. Objective airway artery dimensions compared to CT scoring methods assessing structural cystic fibrosis lung disease. J Cyst Fibros 2017;16:116-23.

13 Rosenow T, Oudraad MC, Murray CP, et al.PRAGMACF. A quantitative structural lung disease computed tomography outcome in young children with cystic fibrosis. Am I Respir Crit Care Med 2015;191:1158-65.

14 Tiddens HA, Rosenow T. What did we learn from two decades of chest computed tomography in cystic fibrosis? Pediatr Radiol 2014;44:1490-5. 